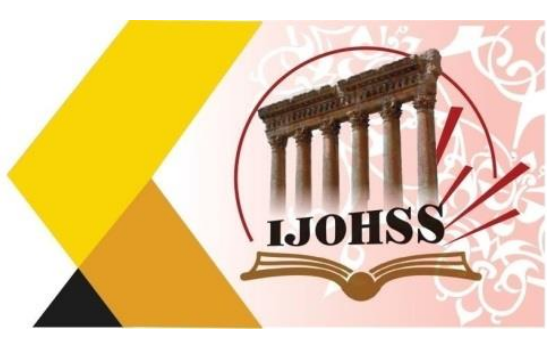

\title{
ثقافة التنظيم في المؤسسة الجامعية العراقية (دراسة في انثرويولوجيا الادارة لجامعة الفرات الاوسط التواهيط التقنية)
}

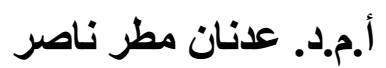

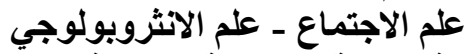 \\ كلية التربية الاساسية - جامعة الانروبولوجي المثنى \\ العراق \\ البريد الاكتروني: adnannaser900@mu.edu.iq
}

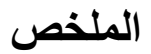

يهدف البحث الى معرفة وفهم ظاهرة ثقافة التنظيم في اطار العلاقة الانتروبولوجية والادارية داخل المؤسسة

الجامعية في المجتمع العراقي من وجهة نظر عينة عشو ائية من اعضاء هيئة تدريس كليات ومعاهد جامعة الفرات الاوسط التقنية(كلية التقنية الادارية، كلية التقنية الهندسية، التقنيات الصحية والطبية)، و المعهد التقني في الكوفة للعام

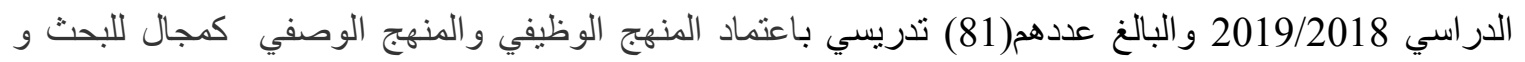
استخدمت الادوات الاحصائية المناسبة للمنهجين المذكورين اعلاه، وتوصل البحث الى مجموعة من النتائج ابرزها وجود نكامل ثقافي واجتماعي في الرؤية الانثروبولوجية والادارية كمدخل في دراسة الظواهر التنظيمية ووصفها وتحليل ابعادها ووضع الحلول الكفيلة بمواجهة مشاكلها من اجل الوصول الى وضع توصيات مناسبة للظاهرة المدروسة اهمها إقامة دورات تدريبية منطورة ومنح فرص أفضل لتطوير مهارات العاملين وخبر اتهم وعلاقاتهم الاجتماعية داخل المؤسسة الجامعية لتعزيز ثقافة التنظيم التي تتحقق بالاعتماد على مجالات ( الثقافة الجماعية، الثقافة التطويرية، الثقافة العقلانية، الثقافة الهرمية ومجال اكتساب المعرفة). 


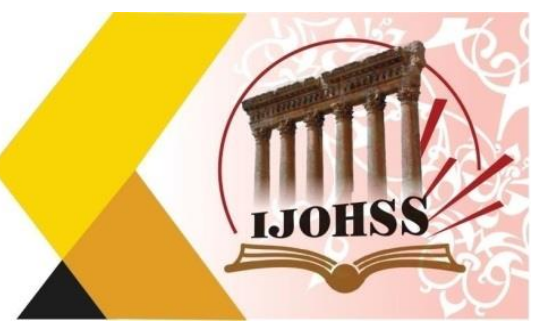

\title{
Culture of Organization in the Iraqi University Institution
}

(A study in the administration anthropology of the AI-furat AL-Awsat Technical University)

\author{
Assist. Prof. Dr. Adnan Mutter Nassir \\ Sociology - Anthropology \\ College of Basic Education University of Al-Muthanna \\ Iraq \\ Email: adnannaser900@mu.edu.iq
}

\begin{abstract}
.
The aim of the research is to know and understand the phenomenon of organizational culture within the framework of the anthropological and administrative relationship within the university institution in Iraqi society from the point of view of a random sample from the faculty members of faculties and institutes of the Middle Euphrates University in the Kufa district, who are (81) teaching. The functional and descriptive method was adopted using the random sample method as a field of research, and the appropriate tools for the two approaches were used as a tool for collecting information. The research reached cultural and social integration in many anthropological and administrative theories as an introduction to the study of organizational phenomena and their description and analysis of their dimensions and the development of solutions to confront their problems in order to reach results that explain the phenomenon studied.
\end{abstract}

Keywords: culture, organization, culture of organization, anthropology, management anthropology, university institution. 


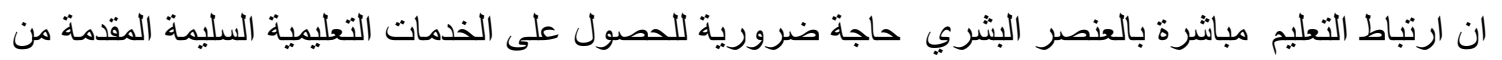

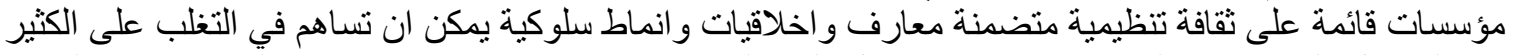

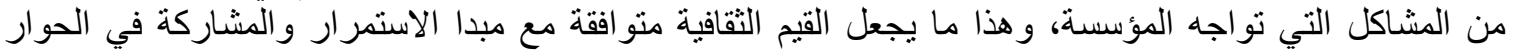

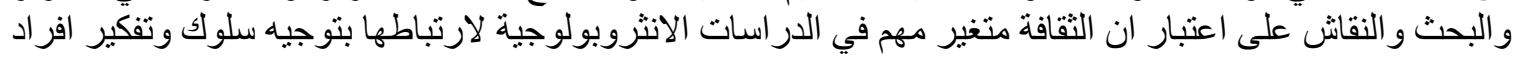

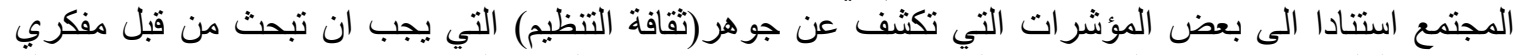

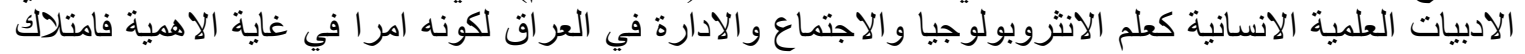

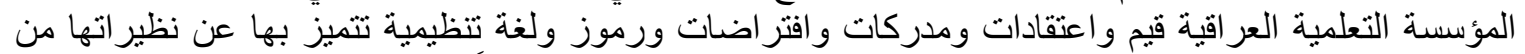

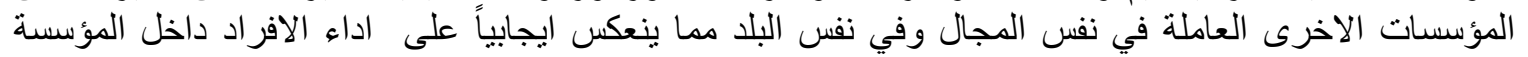

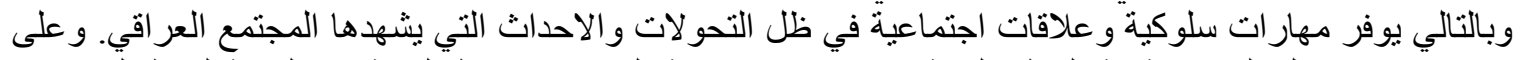

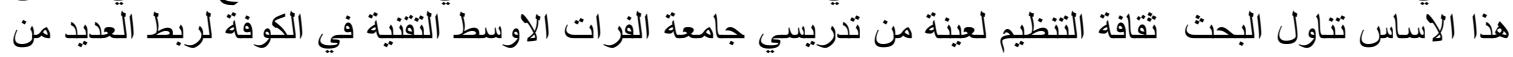

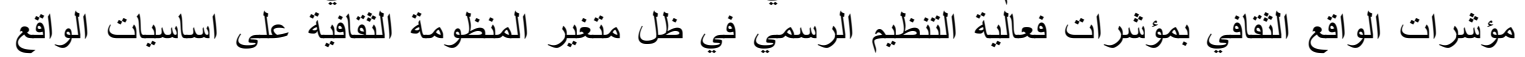

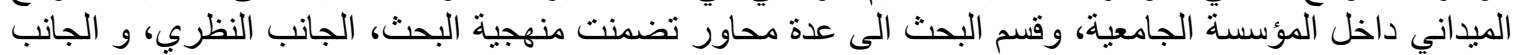

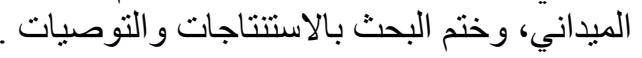

\section{مبحث اول: منهجية البحث ومفاهيمه}

$$
\text { أولاً: منهجية البحث: }
$$

يعد تبني مفاهيم تقافة التنظيم في المؤسسة الجامعية امر ا مهما لان هذا المفهوم يعتبر ظاهرة اجتماعية لا تخلو منها الإيا

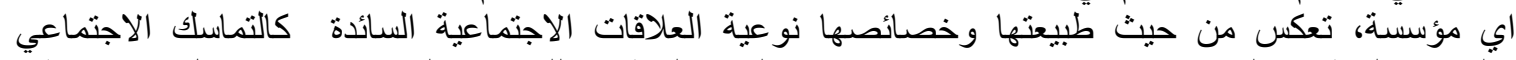

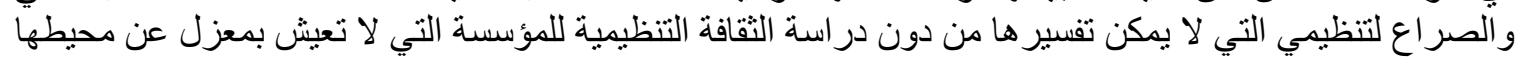

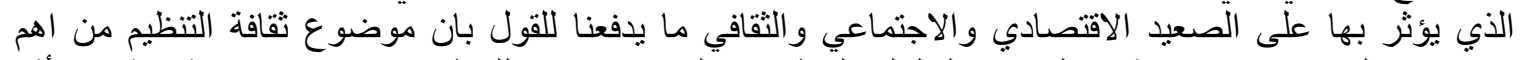

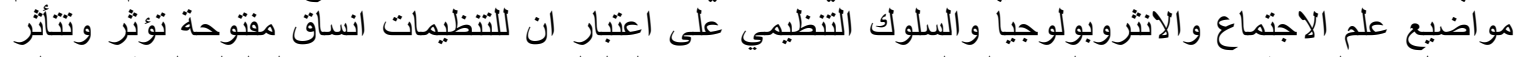

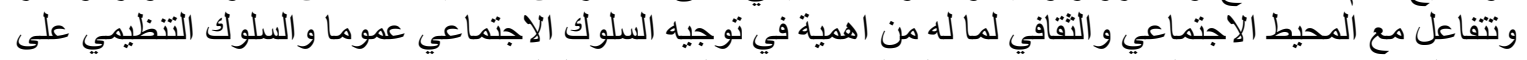

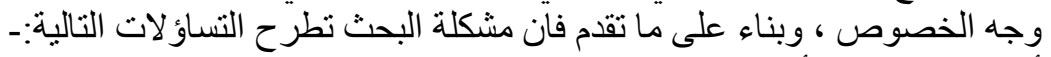

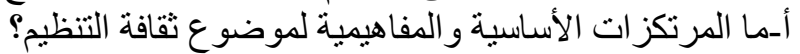

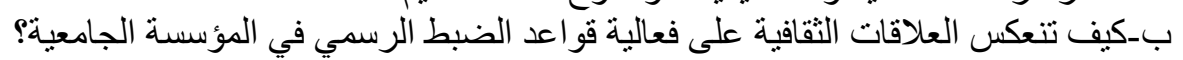
ج- ما مدى إدر الك عينة البحث في الجامعة المبحوثة لمفهوم ثقافة التنظيم في الجامعة المبه

2- طبيعة البحث واهميته: ان طبيعة البحث يمازج بين الفكر الاداري و الانثروبولوجي ضمن تخصص الذص انثروبولوجيا

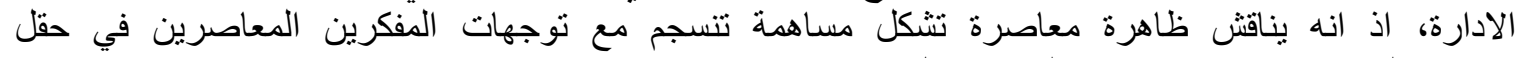

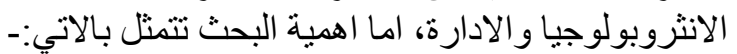

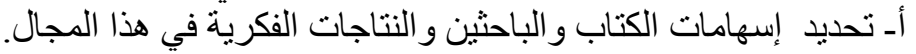

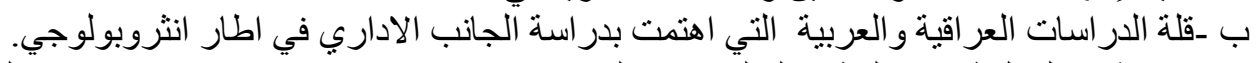

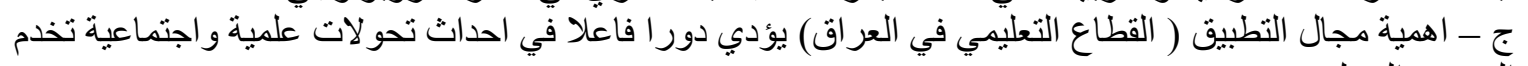
المجتمع المحلي. دـ يفسح البحث مجالا علميا امام الباحثين الاخرين للبحث في ميادين اخرى ذات صله بأنثروبولوجيا الادارة. 
المجلة الحولية اللملوم الآسانية والإمتصاعية

International Journal on Humanities and Social Sciences

website:www.ijohss.com

Email:editor@ijohss.com

العدد (21) (2021

ISSN: 2415 - 4822

Volume (21) May 2021

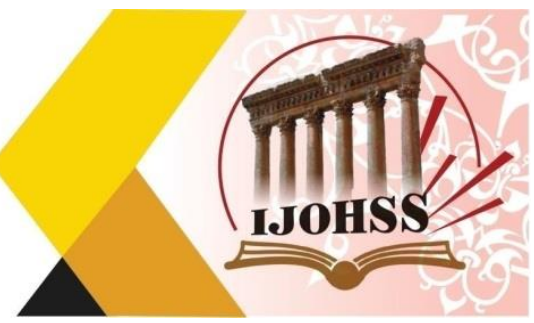

دـ الخروج بمجمو عة توصيات تساهم في رفع مستوى المنظمات التعلمية المحلية بمواضيع البحث المعاصرة المهمة و اللازمة لعمل المنظمات التعليمية الناجحة.

4- دوافع اختيار الموضوع: - 1

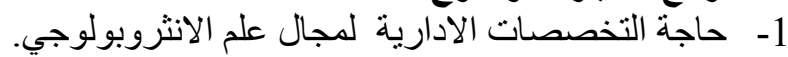

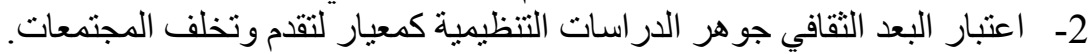

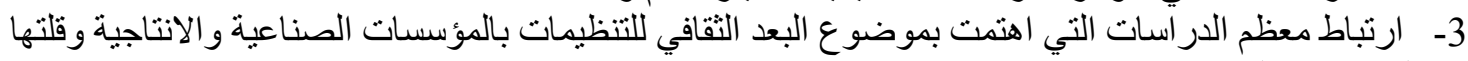
في المؤسسات الجامعية.

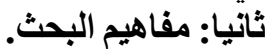

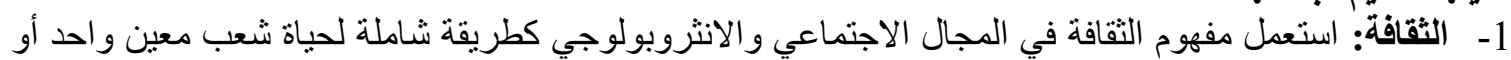

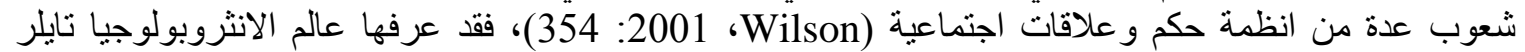
(Edward Taylor)

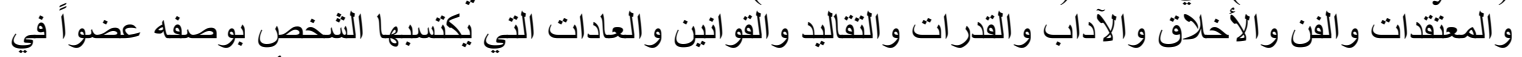

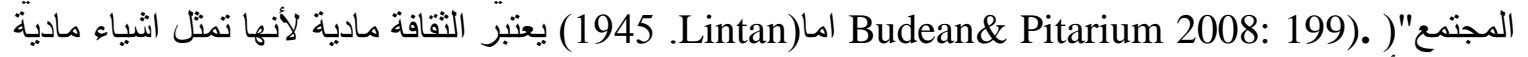

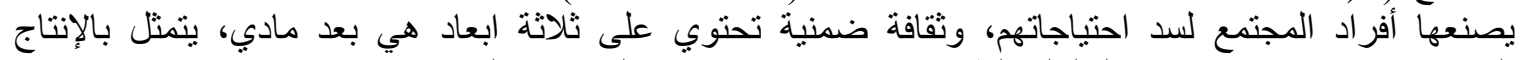

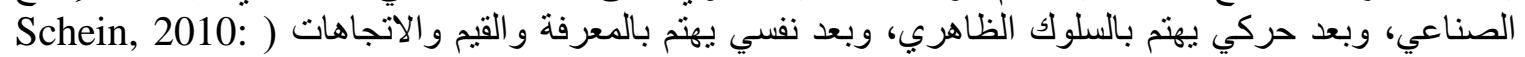
و20).

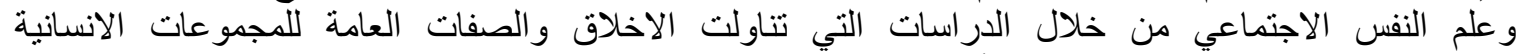

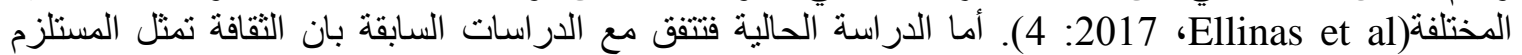

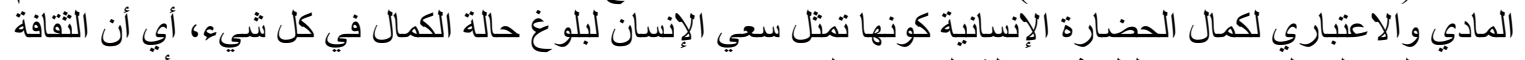

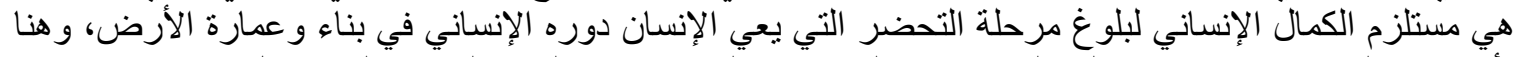

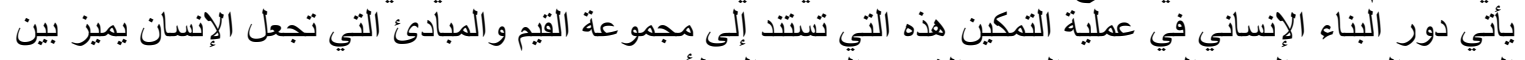

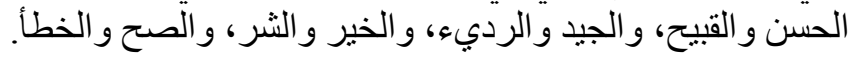

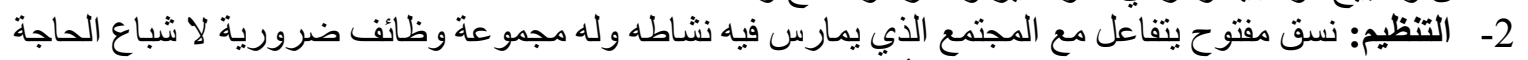

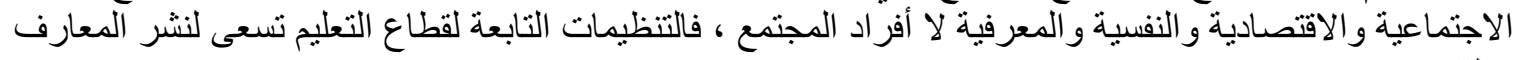

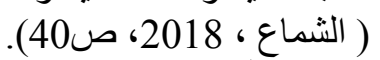
3- ثقافة التظظيم: عرفها معجم مصطلحات العلوم الإدارية الثقافة بأنها البيئة المحيطة بالإنسان بما فيها فيأ النتاج

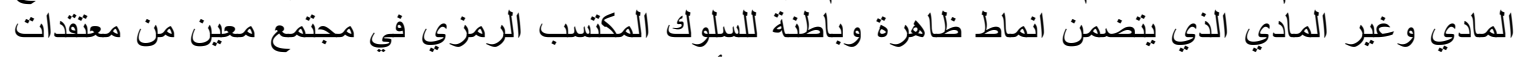

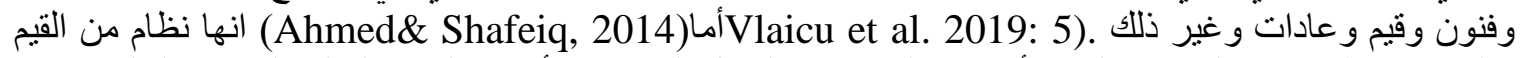

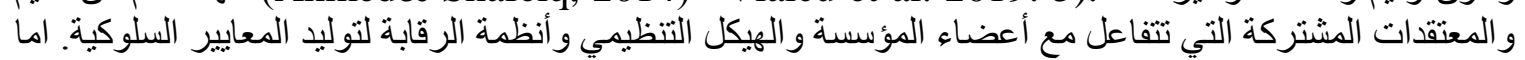
2015، Lapina et al) (Wahyuningsih) 2018، Štemberger et al)

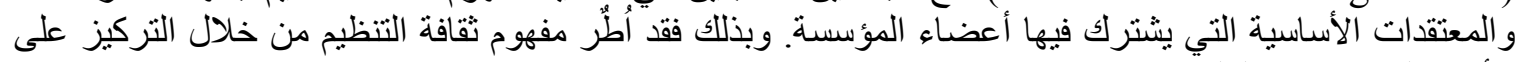

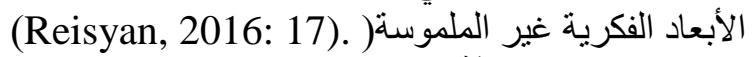

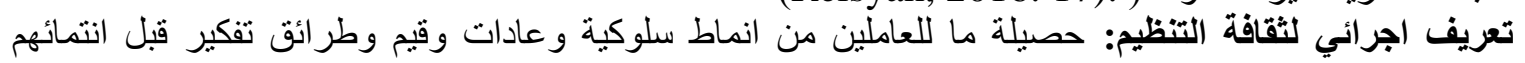

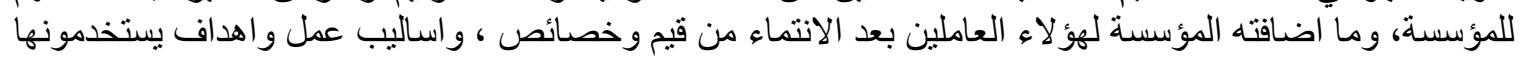

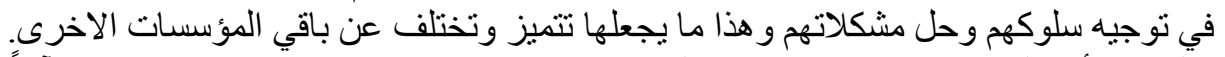

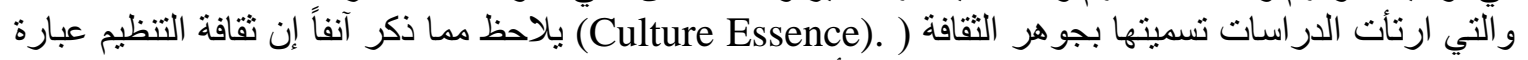

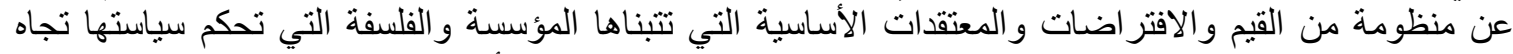

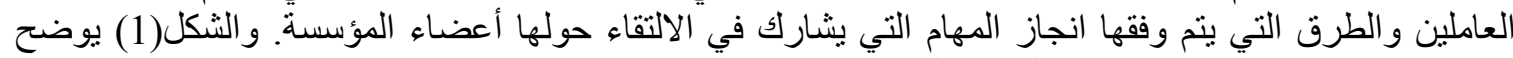

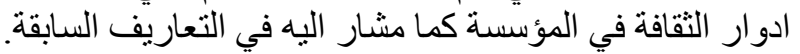



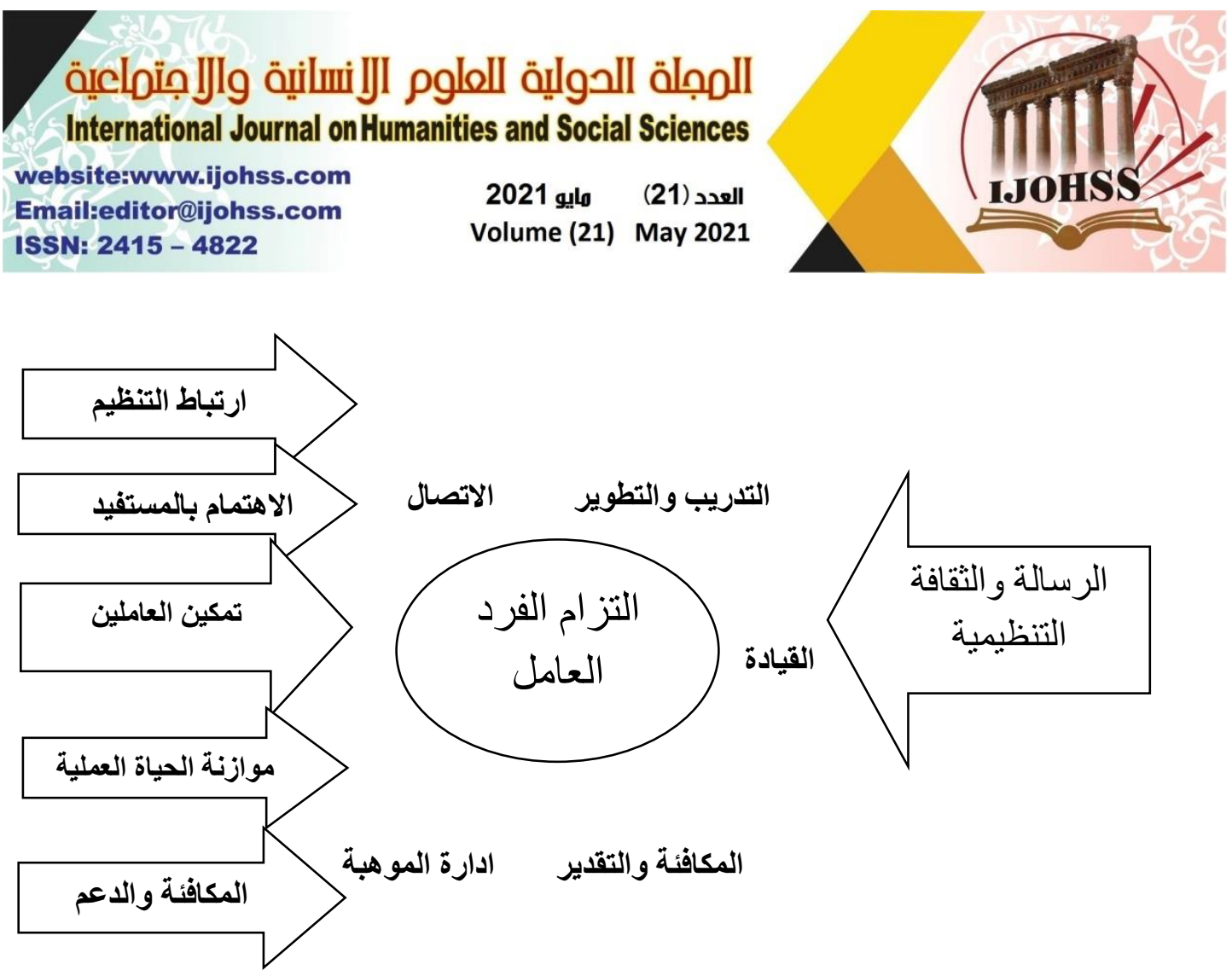

الثكل (1) دور الثقافة في المؤسسة

Source (Taneja et al,2015).

4- الانثروبولوجيا : العلم الذي يهتم بدراسة الانسان باعتباره كائن عضوي يعيش في مجتمع تسوده نظم اجتماعية

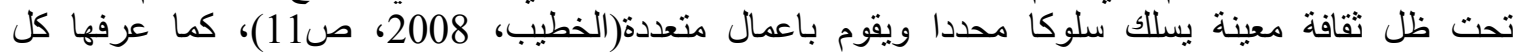

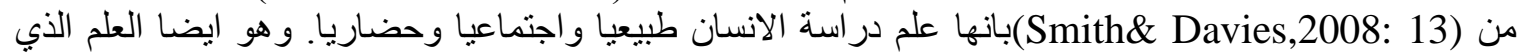

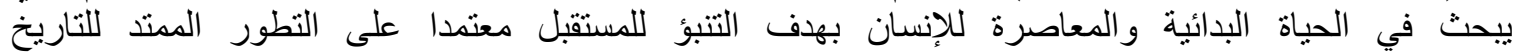

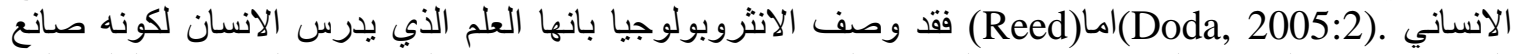

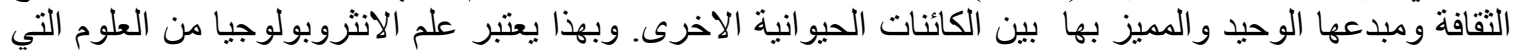

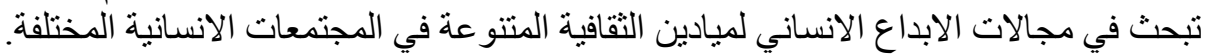

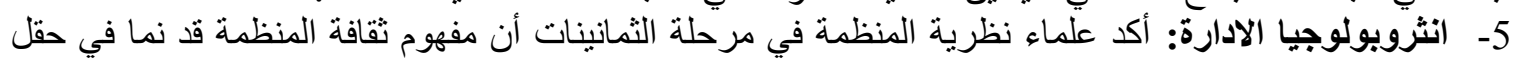

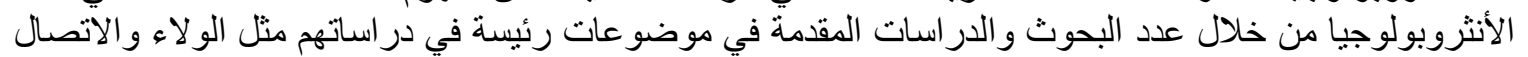
(Athayde) الانثروبولوجية للثقافة، فقد أوضح كل من (Narayanan \& Nath,1993,446-447) بأنها "ثقافة شعب معنين

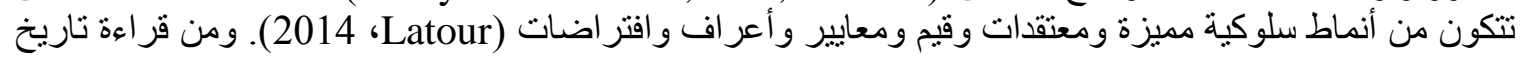

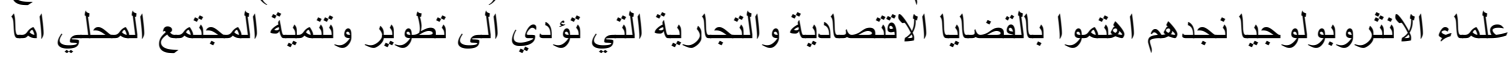

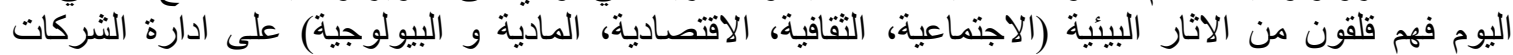

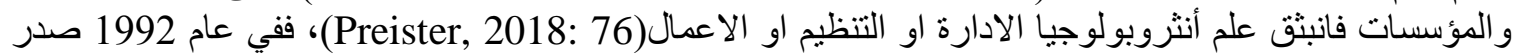

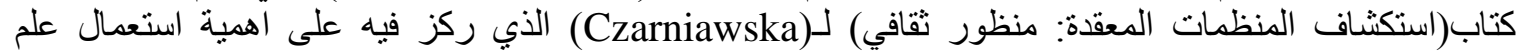

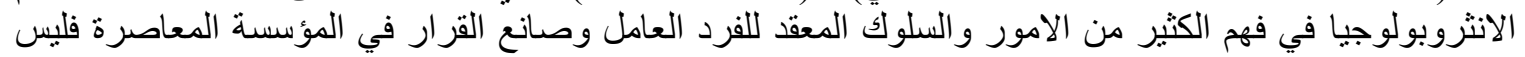

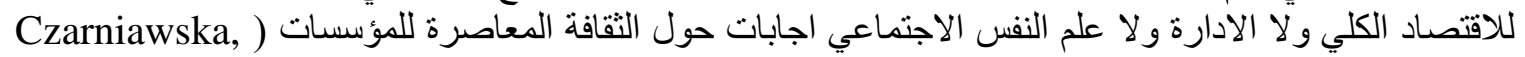

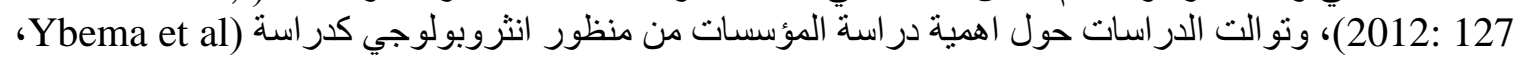
2009) التي ركزت على الثقافة الثعبية لأفر اد التنظيم الاداري. 


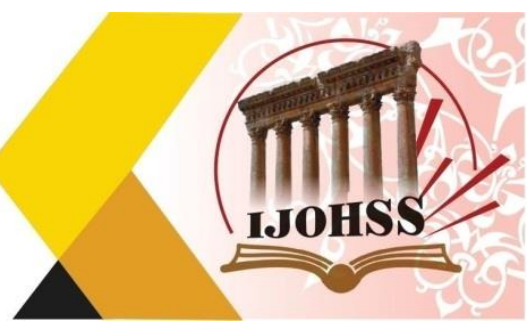

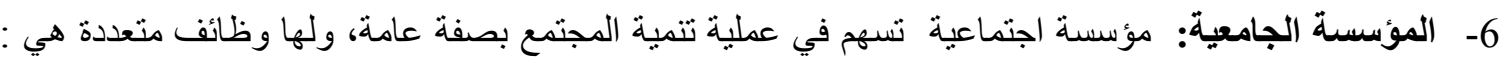

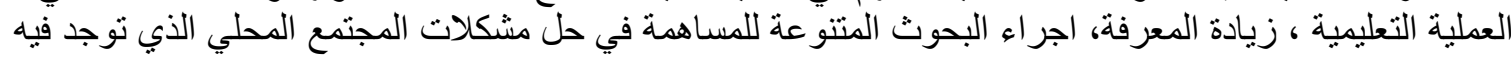

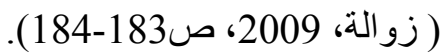
التعريف الاجرائي للمؤسسة الجامعية: مجمع جامعة الفرات الاوسط التقنية التابعة لوزارة التعليم العالي والبحث

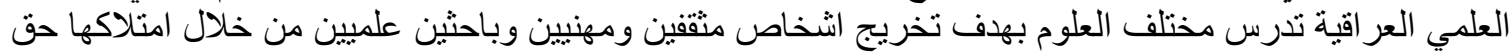
منح الآدرجات العلمية الاكاديمية يتم تسيير ها من قبل نخبة جامعية من دكاترة واساتذة وباحثين.

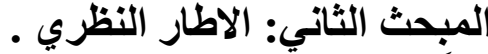

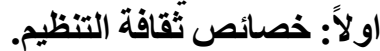

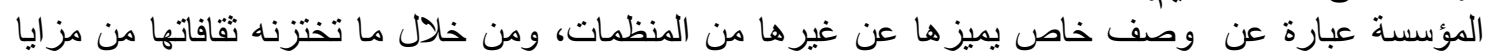

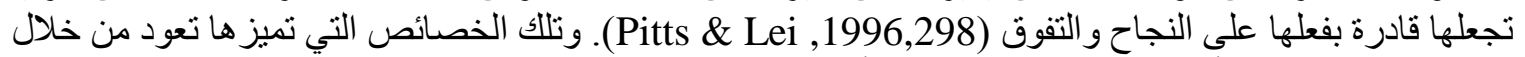

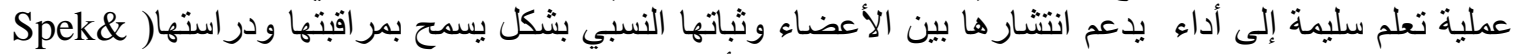

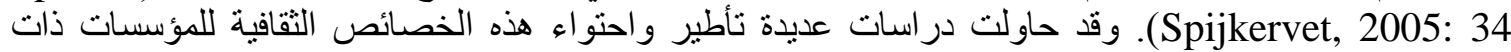

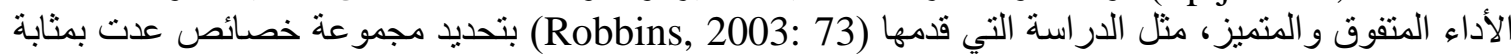

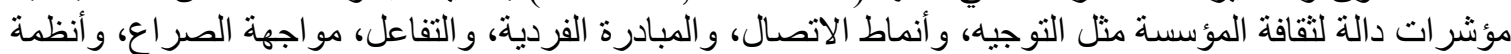

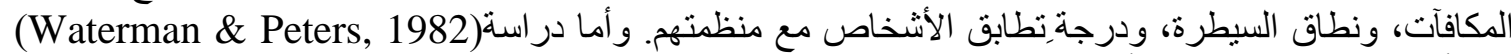

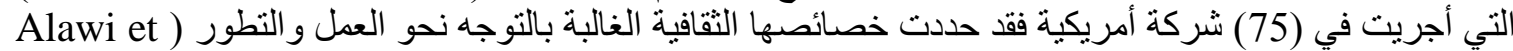

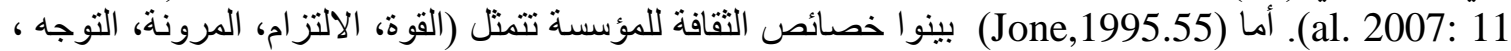

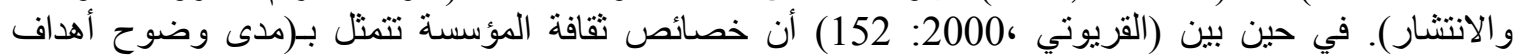

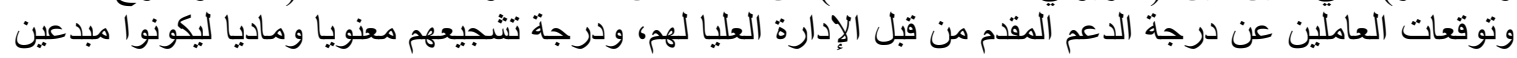

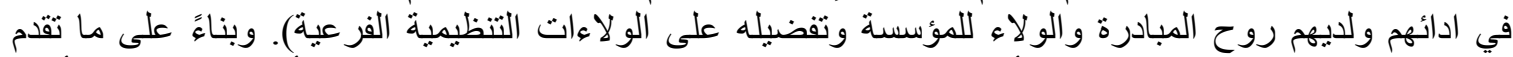

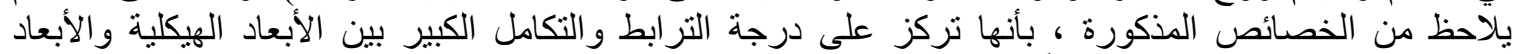
السلوكية في المؤسسة، اذ يعد مؤشر اً لمدى التعائه تركن على والعلاقات التبادلية الأفقية و العمودية.

ثانيا: النظريات المفسرة للبحث.

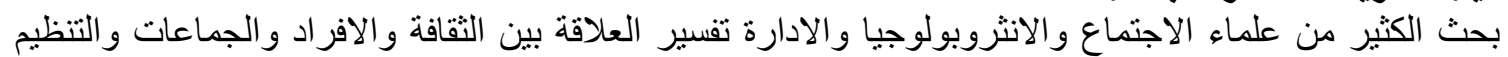

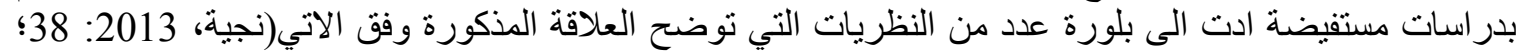

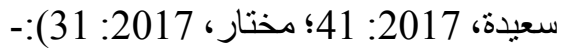

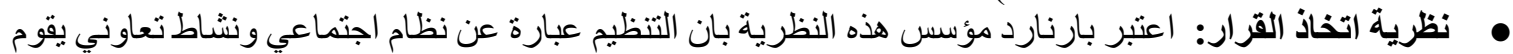

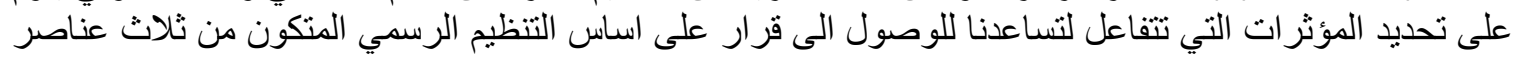

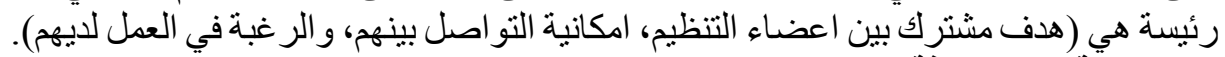

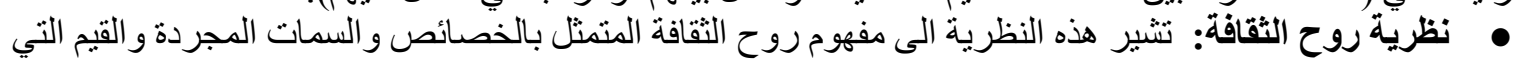

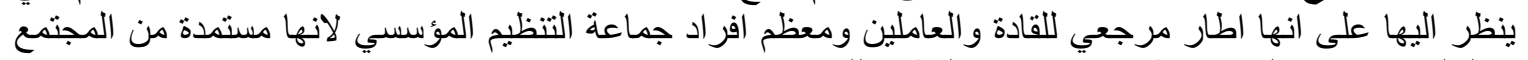

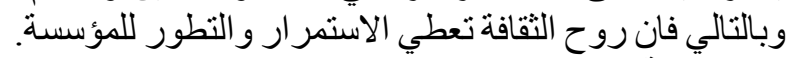

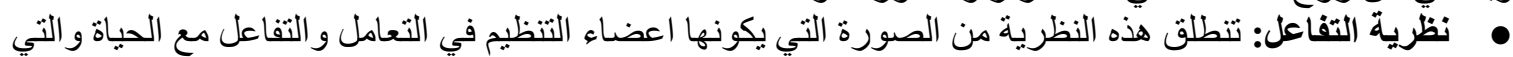

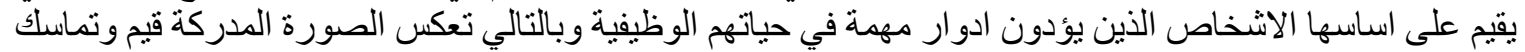

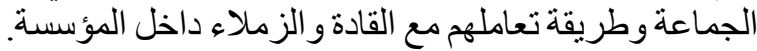

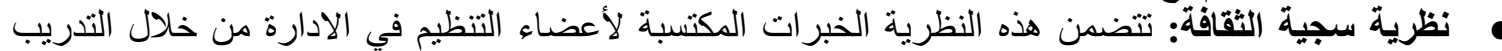

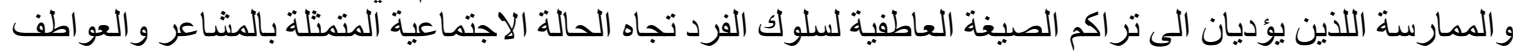

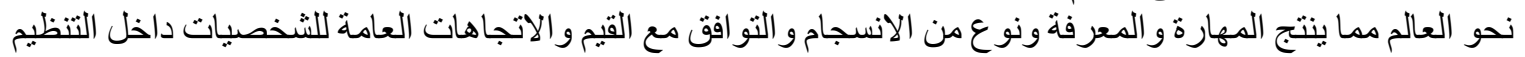

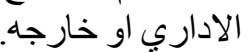

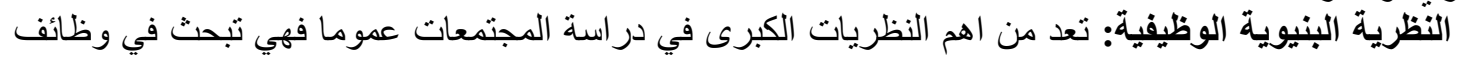

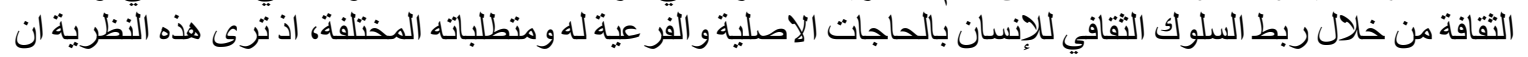




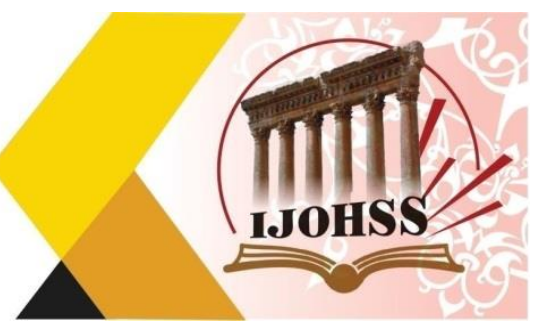

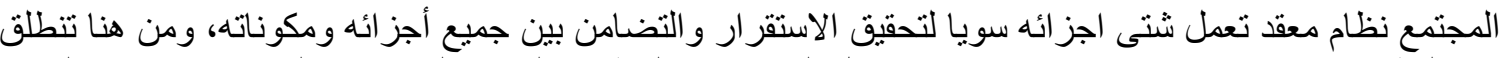

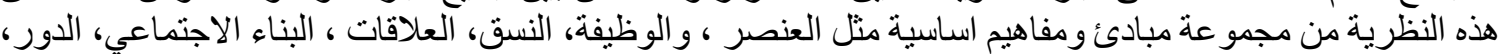

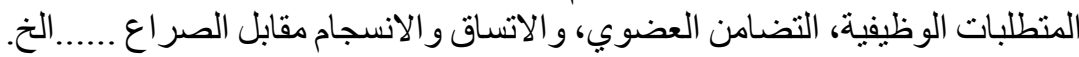

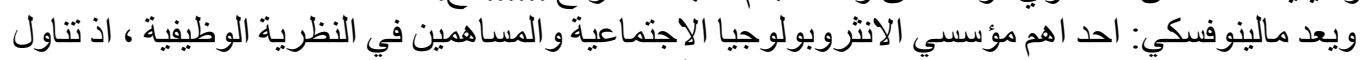

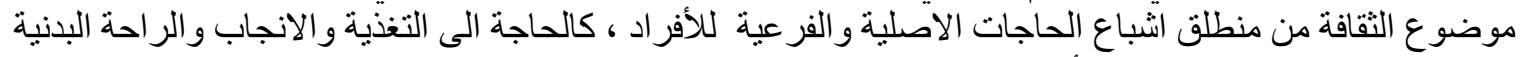

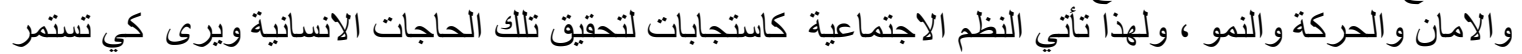

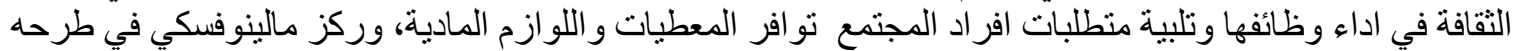

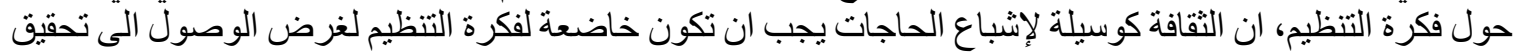

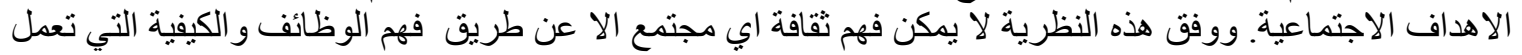

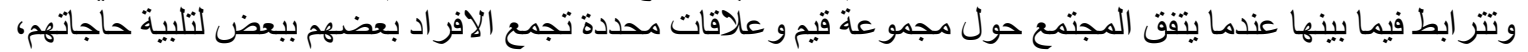

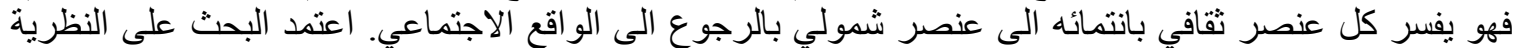

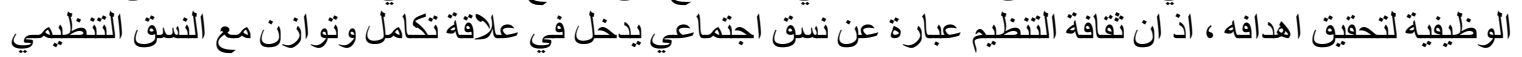

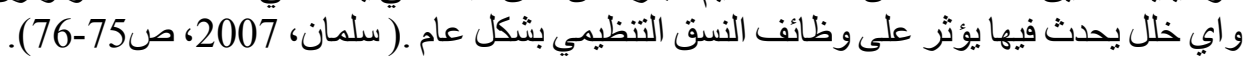

$$
\text { المبحث الثالث / الجاتب الميداني ـ }
$$

يتكون مجتمع البحث من الهيئة التدريسية في المؤسسات التعليمية التابعة لجامعة الفرات الاوسط التواتية التقنية في قضاء

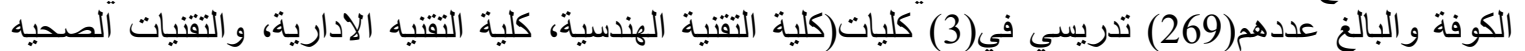

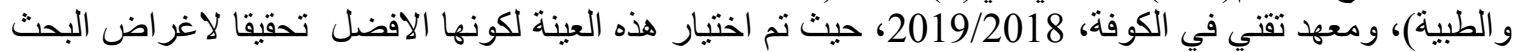

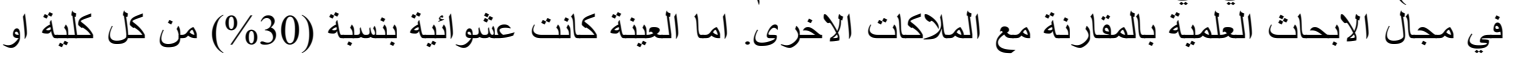

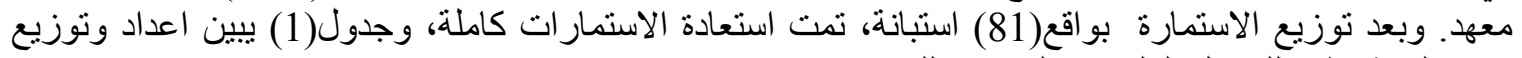

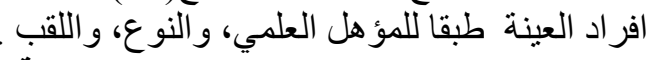

\begin{tabular}{|c|c|c|c|c|c|c|c|c|c|c|c|c|c|}
\hline \multicolumn{4}{|c|}{ اللقب العلمي } & \multicolumn{2}{|c|}{ الجنس } & \multicolumn{3}{|c|}{ التحصيل العلمي } & \multirow[b]{2}{*}{ العشينة } & \multirow[b]{2}{*}{ التدريسين } & \multirow{2}{*}{ و المعاهد } & \multirow[b]{2}{*}{$\begin{array}{l}E \\
\underline{E} \\
\underline{E} \\
\underline{E}\end{array}$} & \multirow[t]{2}{*}{ ت } \\
\hline $\begin{array}{l}5 \\
\xi \\
\xi \\
\varepsilon \\
5 \\
5\end{array}$ & $\begin{array}{l}\xi \\
\xi \\
\xi\end{array}$ & $\begin{array}{l}\hbar \\
\xi \\
\xi \\
\underline{\xi}\end{array}$ & $\underline{L}$ & انتى & ذكر & $\stackrel{0:}{\underline{t}}$ & $\xi$ & $\begin{array}{l}\frac{2}{5} \\
\frac{4}{2}\end{array}$ & & & & & \\
\hline 9 & 7 & 3 & - & 9 & 10 & 8 & 11 & - & 19 & 65 & الهندسيه & $\overline{\bar{y}}$ & 1 \\
\hline 3 & 3 & 2 & 1 & 5 & 4 & 4 & 4 & 1 & 9 & 29 & الاداريه & ] & 2 \\
\hline 1 & 4 & 3 & - & 2 & 6 & 3 & 5 & - & 8 & 26 & والطبية & 司 & 4 \\
\hline 12 & 17 & 16 & - & 18 & 27 & 15 & 28 & 2 & 45 & 149 & تقنية & التقنية & 5 \\
\hline 25 & 31 & 24 & 1 & 34 & 47 & 30 & 48 & 3 & 81 & 269 & & المجا & \\
\hline
\end{tabular}

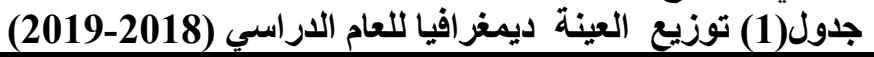

يتبين من الجدول(1 ) أن اغلب العينة حصلوا على شهادة الماستر بلغ عددهم(48) تدريسي من ثم حملة شهاده

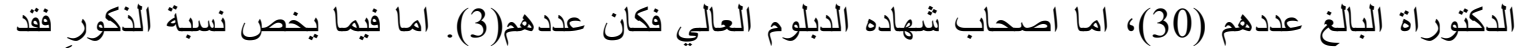

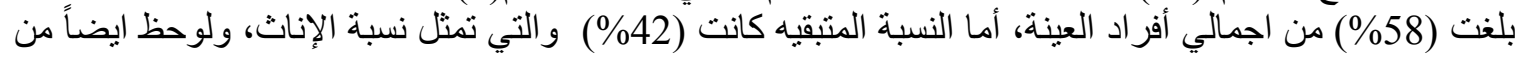


website:www.ijohss.com

Email:editor@ijohss.com

ISSN: 2415 - 4822

مدرس مساعد، وان عدد حملة لقب استاذ
العدد (21) (2021 Volume (21) May 2021

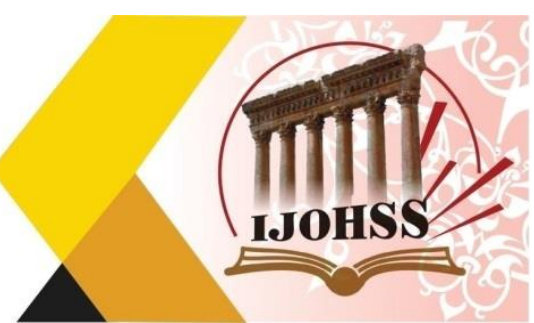

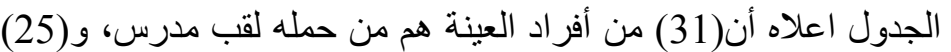

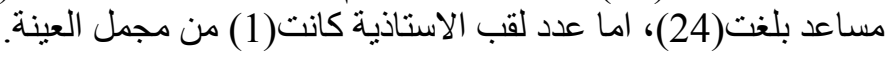

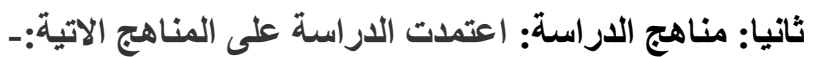

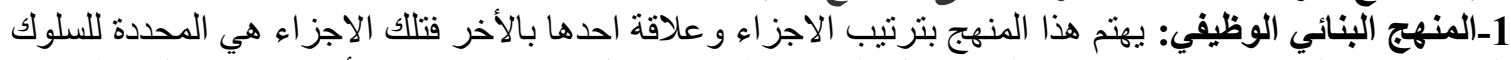

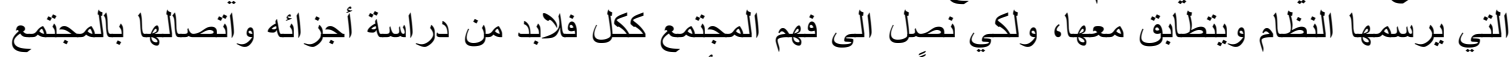

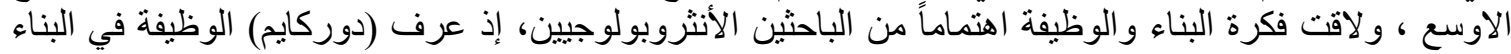

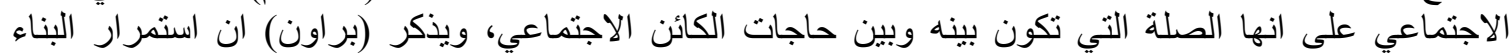

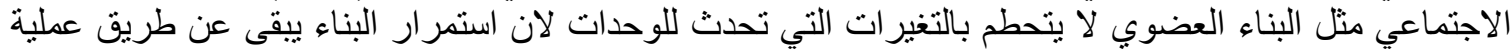

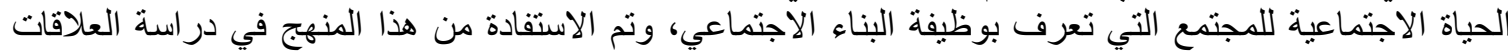

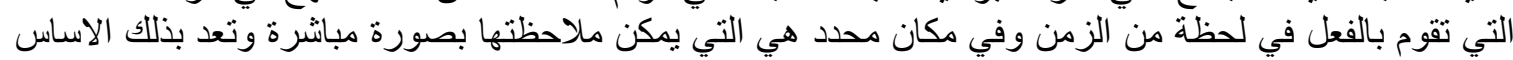
الاول لدر اسة البناء الاجتماعي في المؤسسة الجامعية والتعرف على العي العو امل الثقافية والاجتماعية المختلفة المؤثرة في الأي

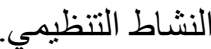

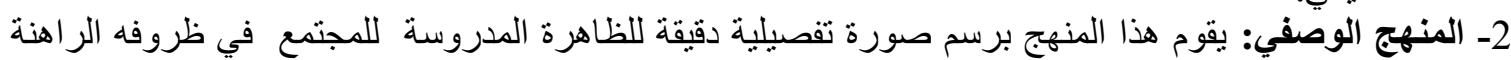

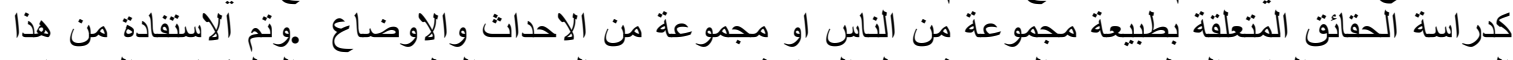

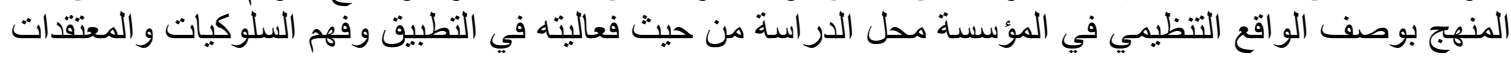

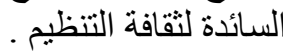
ثالثا: ادوات جمع البيانات.

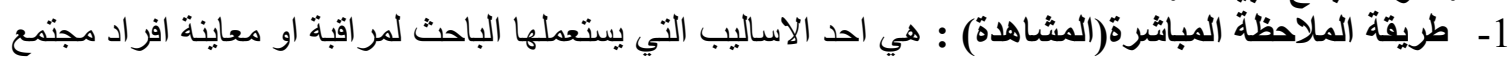

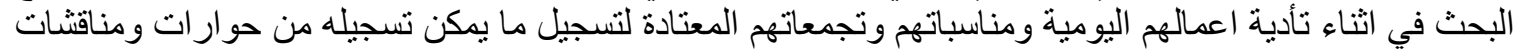

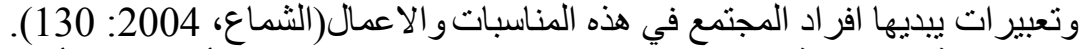

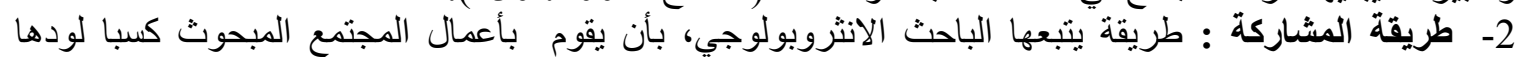

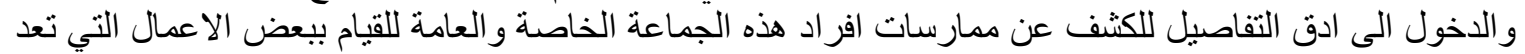

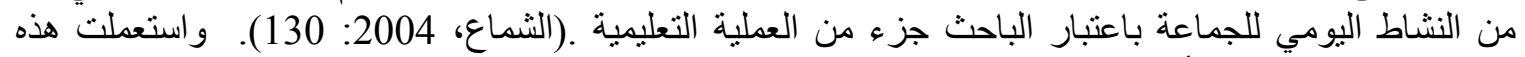

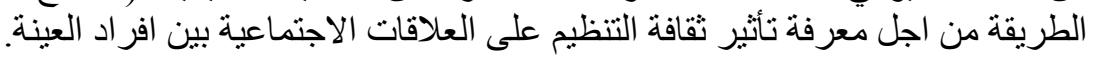

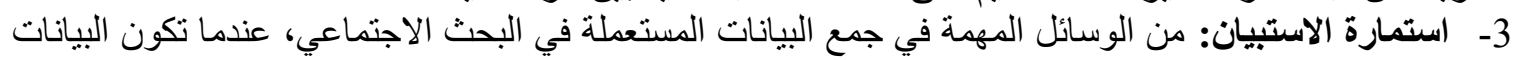

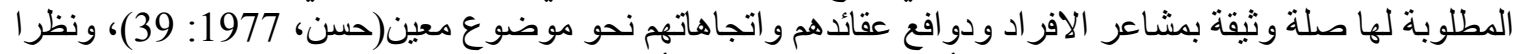

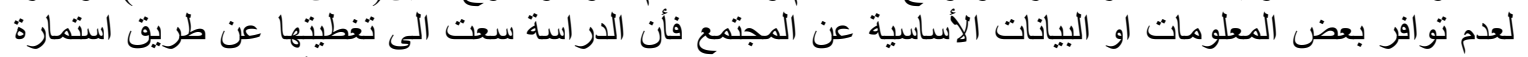

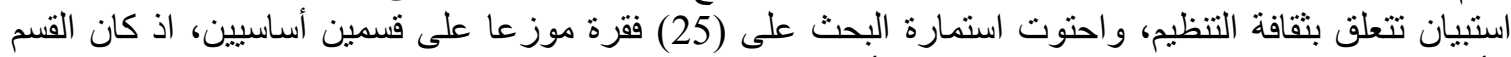

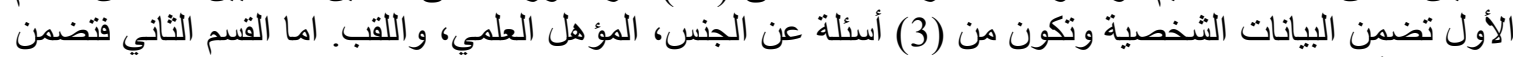

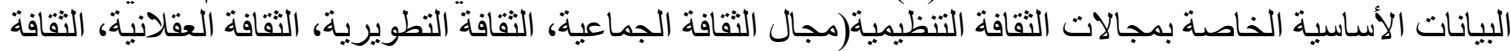

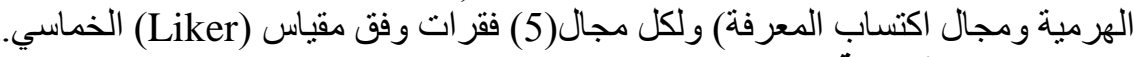

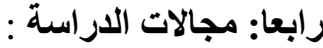

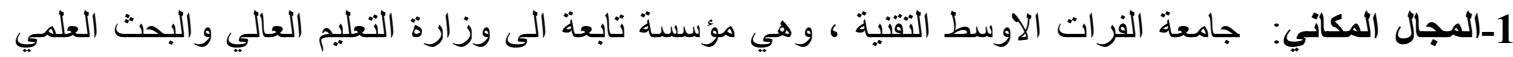

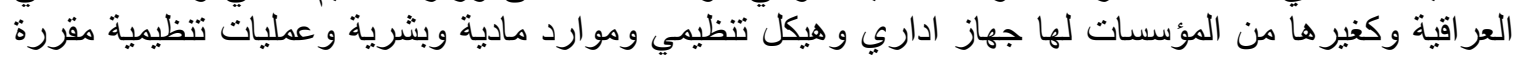

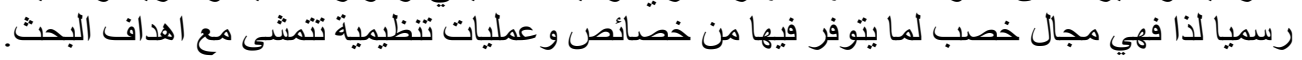

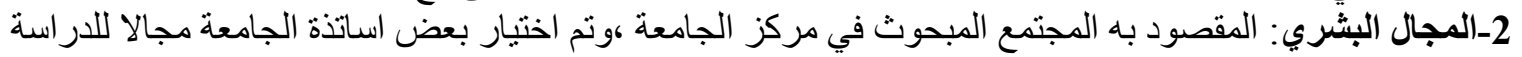
طبقا للعينة المنتخبة. 3-المجال الزماني: غطى الجهد الميداني المرحلة الزمنية الممتدة ما بين 2019/3/1 ولغاية 2019/5/1. 


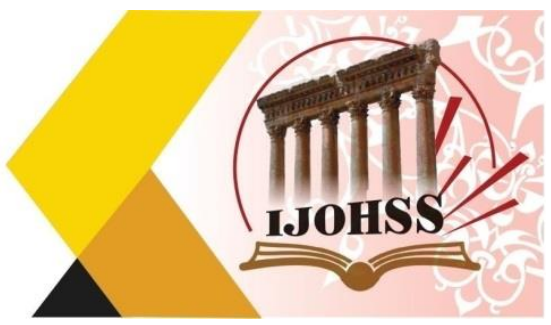

خامسا: إجابات المبحوثين : إئ

تم وصف وتفا: إجفير وتحليل إجابات أفراد العينة على النحو الآتي:

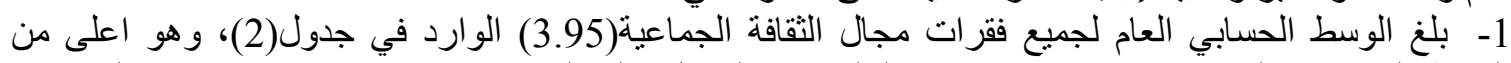

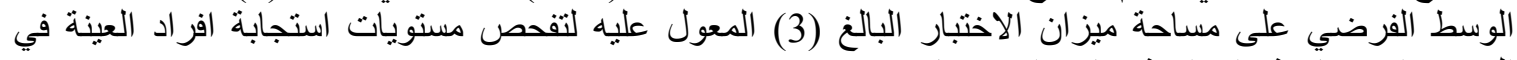

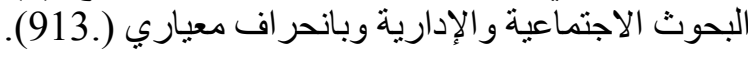

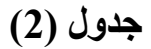

اوساط حسابية وانحر افات معيارية لفقرات الثقافة الجماعية في العينة (81= )

\begin{tabular}{|c|c|c|c|c|}
\hline الإجابة & الانحياري & الحسابي & 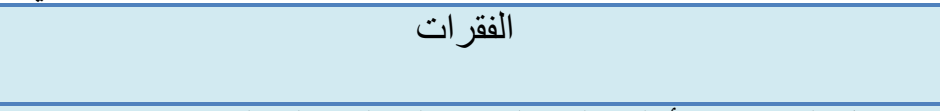 & $ت$ \\
\hline 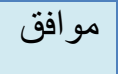 & 949 & 4.02 & تفضل الجامعة مبدأ المصلحة العامة على المصالح الخاصة. & 1 \\
\hline مو افق & .884 & 4.14 & سة بحرية الراي و المشاركة الجماعية . & 2 \\
\hline 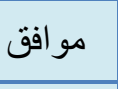 & 1.001 & 3.83 & يشارك العاملون في الجامعة زملائهم في المناسبات الاجتماعبة المختلفة & 3 \\
\hline 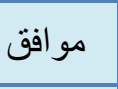 & 963 & 3.87 & تعد الجامعة كالعائلة الو احدة & 4 \\
\hline 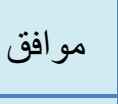 & 1.045 & 3.91 & تشتمع الجامعة العلاقات غير الرسمية بين العاملين لبث روح جو & 5 \\
\hline 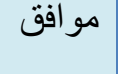 & 913 & 3.95 & مجموع & \\
\hline
\end{tabular}

2- تم قياس مجال(الثقافة الجماعية) بخمس فقرات، وكانت من أبرز الفقرات التي أسهمت في إغناء هذا المجال هي

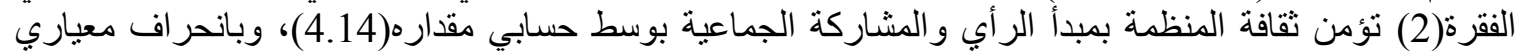

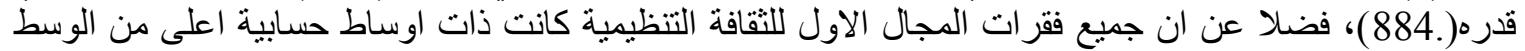

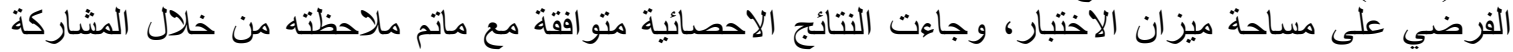

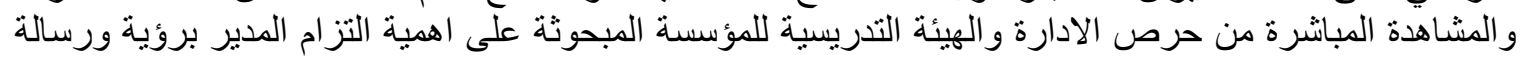

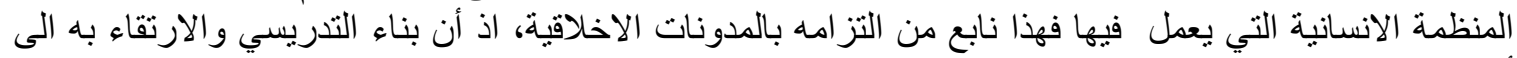

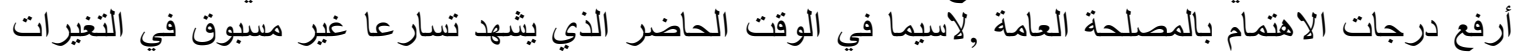

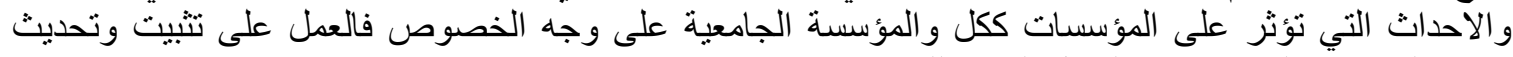

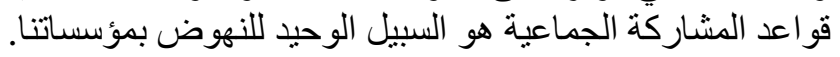

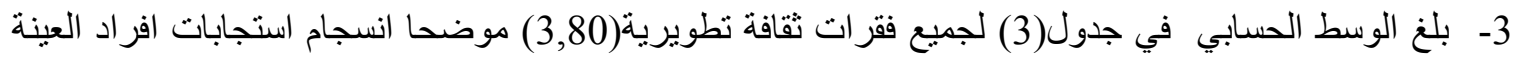

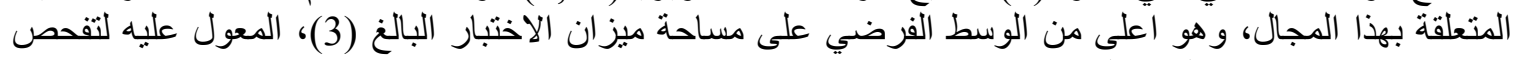

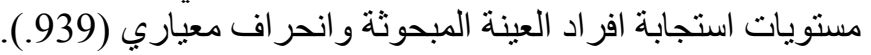




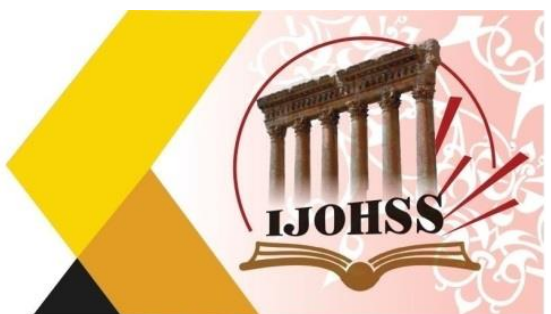

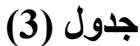

اوساط حسابية وانحر افات معيارية لفقرات الثقافة التطويرية في عينة البحث(81=N)

\begin{tabular}{|c|c|c|c|c|}
\hline الإجاهة & الانحر افياري & الحسابي & 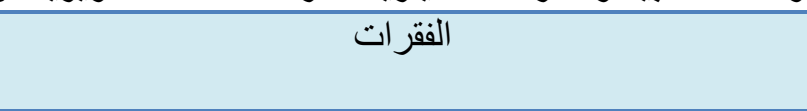 & $ت$ \\
\hline 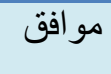 & .858 & 4.01 & ترفد الجامعة المجتمع بأصحاب الكفاءات العلمية & 1 \\
\hline 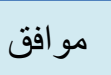 & 1.007 & 3.73 & تعطي الجامعة مساحه اكثر للبعثات العلمية لتحصيل كل نافع. & 2 \\
\hline 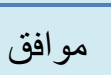 & .982 & 3.74 & تضع الجامعه خطط مستقبلية لتطوير العملية التعليمية & 3 \\
\hline 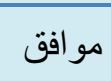 & .990 & 3.75 & تطور الجامعة مهار ات العاملين في كل المجالات الموجوده & 4 \\
\hline 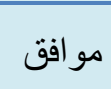 & .86293 & 3.80 & تكرم الجامعة العاملين المبدعين & 5 \\
\hline 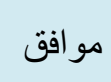 & .939 & 3.80 & مجموع & \\
\hline
\end{tabular}

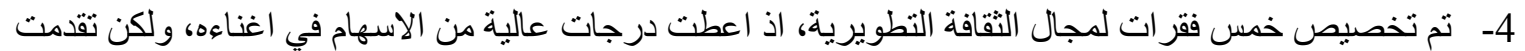

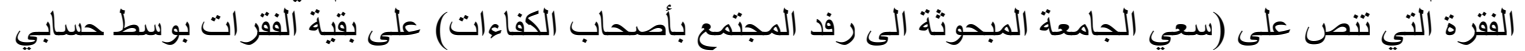

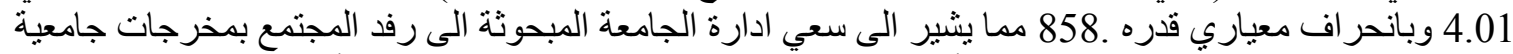

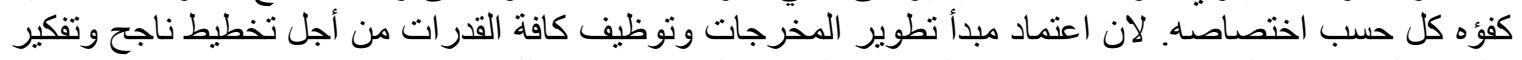

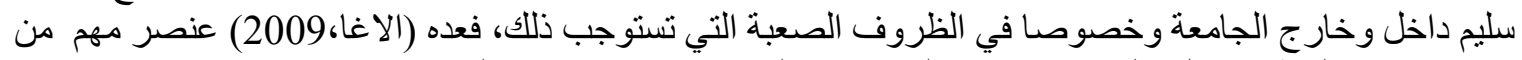

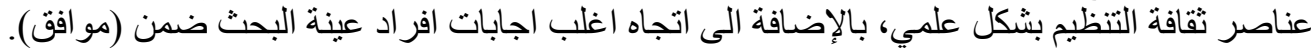

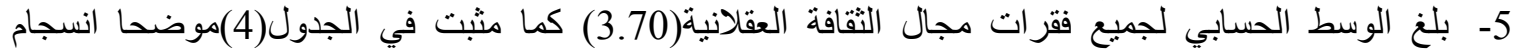

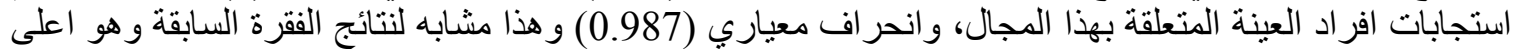
من الوسط الفرضي على مساحة ميزان الاختبار البالغ (3)، المعول عليه لتفحص مستويات استجابة افراد العينة العينة .

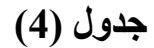

\begin{tabular}{|c|c|c|c|c|}
\hline 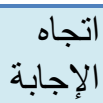 & 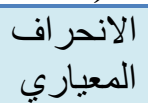 & الحسابي & 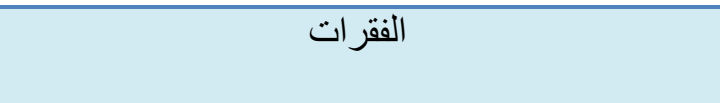 & $ت$ \\
\hline 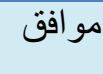 & 1.119 & 3.68 & تحدد الجامعة الأهداف و التطلعات بشكل و اضح ودقيق & 1 \\
\hline 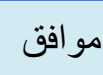 & .967 & 3.71 & تجمع الجامعة بين الاصالة والمعاصرة . & 2 \\
\hline 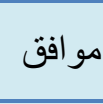 & .939 & 3.73 & للجامعة اولويات ت تتناسب مع امكاناتها المادية & 3 \\
\hline 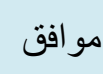 & 1.011 & 3.71 & تتو افق منطلبات الجامعة مع قدر ات العاملين. & 4 \\
\hline 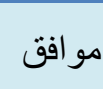 & .90147 & 3.70 & تدعم الجامعة الانجاز ات الاكاديمية و البحثية & 5 \\
\hline 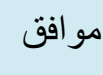 & 0.987 & 3.70 & مجموع & \\
\hline
\end{tabular}




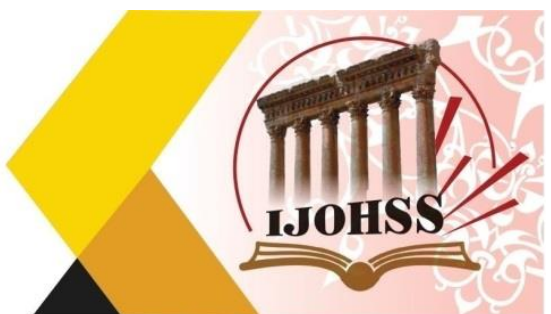

6- جاءت اغلب اجابات افر اد عينة البحث ضمن (مو افق)، اذ كانت اعلى فقرات مجال الثقافة العقلانية ضمن الوسط

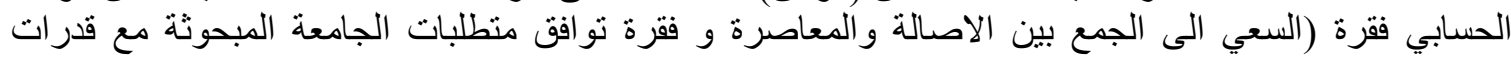

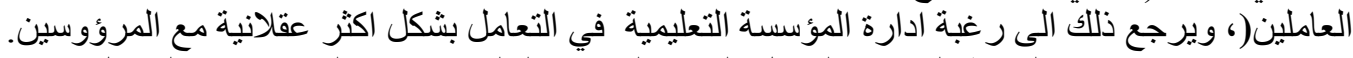

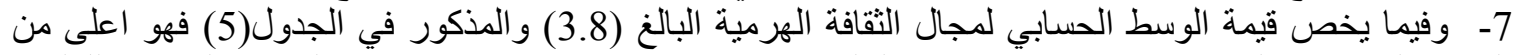

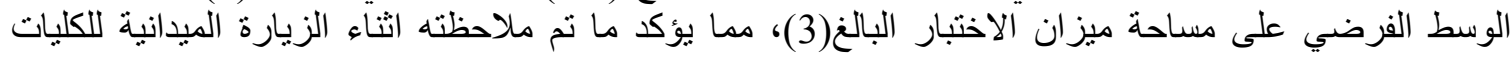

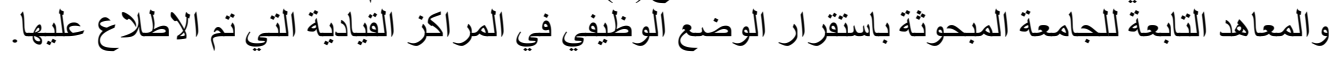

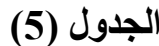

\begin{tabular}{|c|c|c|c|c|}
\hline ال الجاهة & ال الانحر اف ال المعباري & 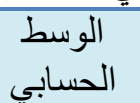 & 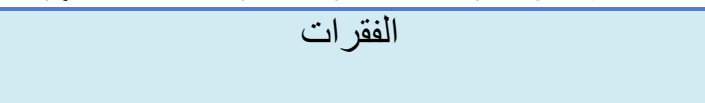 & $ت$ \\
\hline 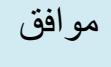 & .885 & 3.83 & تو افق و انسجام وظيفي مع المؤهلات و الخبرات & 1 \\
\hline 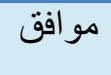 & .850 & 3.74 & المر اكز القيادية في الجامعة تتسم بالاستقر ار الوظيفي & 2 \\
\hline مو افق & .892 & 3.80 & السلوك الاداري في الجامعة يمتاز بالانضباطية & 3 \\
\hline مو افق & .833 & 3.86 & تقوم ادارة الجامعة اداء العاملين وفق معايير & 4 \\
\hline مو افق & .800 & 3.77 & توز ع الجامعة الفرص مو المكافآت على الموظفين & 5 \\
\hline مو افق & 0.852 & 3.8 & مجموع & \\
\hline
\end{tabular}

8- وتبين من نتائج الجدول (6) ان قيمة الوسط الحسابي لجميع فقرات (اكتساب المعرفة) وهو اعلى العي من الوسط

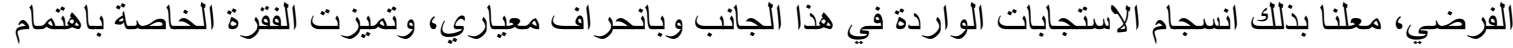

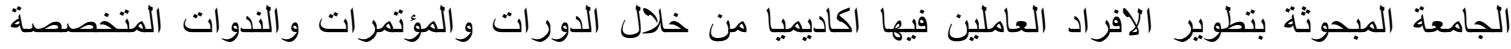

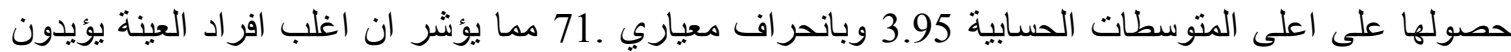

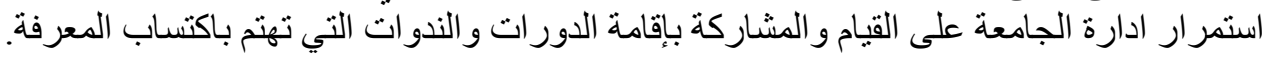

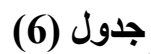
الأوساط الحسابية والانحر افات المعيارية لفقرات اكتساب المعرفة في عينة البحث (N =8)

\begin{tabular}{|c|c|c|c|c|}
\hline 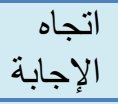 & 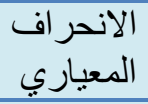 & 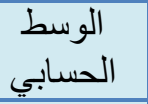 & 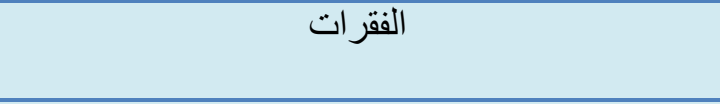 & $ت$ \\
\hline مو افق & .717 & 3.95 & 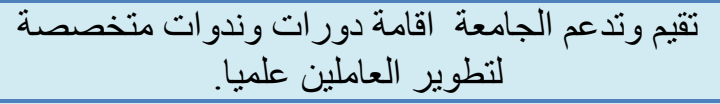 & 1 \\
\hline مو افق & .829 & 3.80 & الظربع الجامعة حاجات الاحوال. العاملين المختلفة تحت كل & 2 \\
\hline مو افق & .750 & 3.83 & تنظم الجامعة اجتماعات دورية منتظمة داخل المؤسسة & 3 \\
\hline مو افق & .819 & 3.79 & نظام اتصال فعال. تيادل المعرفة ادارة و العاملين في الجامعة وفق & 4 \\
\hline 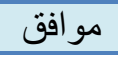 & .824 & 3.74 & تتجاوز الجامعة الاطر الطائفية والمناطقية وتشجع & 5 \\
\hline
\end{tabular}




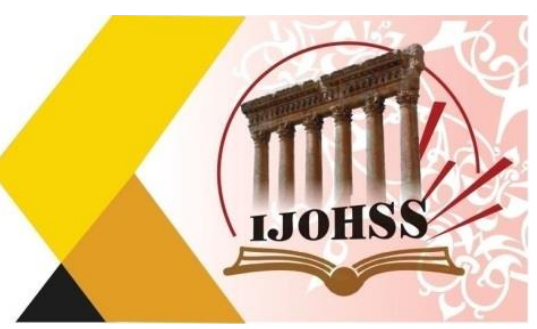

\begin{tabular}{|l|l|l|c|c|}
\hline & & & (التعددية الفكرية والثقافية في المجتمع المحلي & \\
\hline & 0.787 & 3.82 & \\
\hline
\end{tabular}

1- اقتصرت الدراست التات الاولى التي تناولت موضوع ثقافة التنظيم على الجانب الاداري والاجتماعي من دون

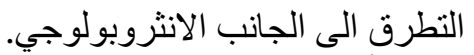

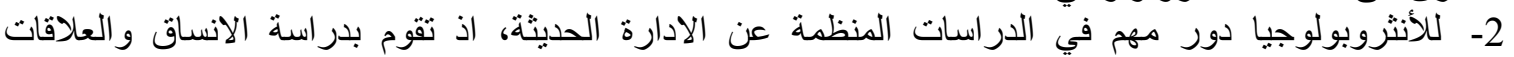

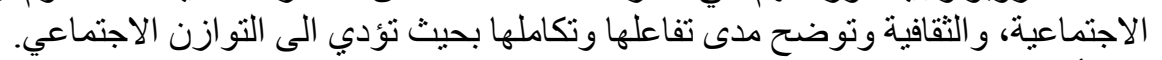

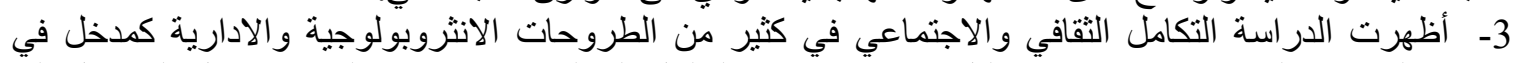

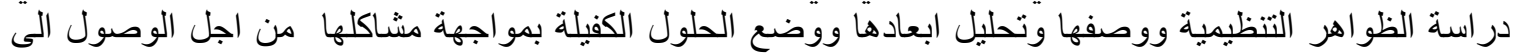
نتائج تفسر الظاهرة المدروسة. 4- دلت نتائج البحث الميدانية على اهتمام ادارة الجامعة المبحوثة بمجالات ثقافة التنظيم (مجال الثقافة الجماعية،

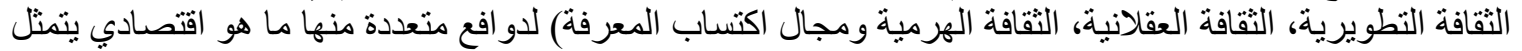

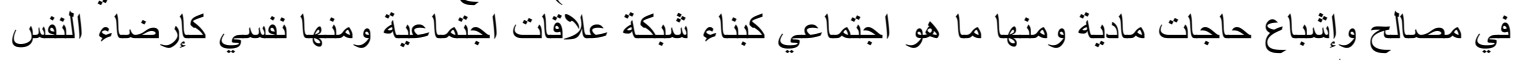
و الاحساس بالمكانة.

5- اظهرت النتائج الميدانية للبحث اهتمام الجامعة المبحوثة في دعم ثقافة التنظيم، من خلال ملاحظة المؤتمرات

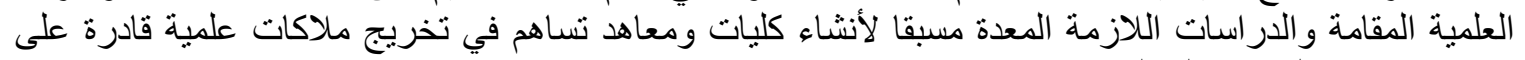
ادارة مؤسسات المجتمع المحلي.

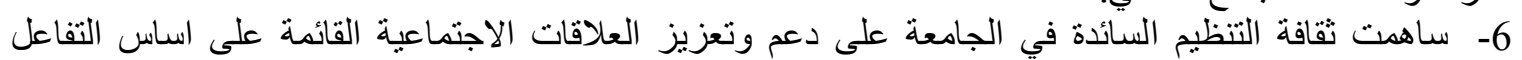

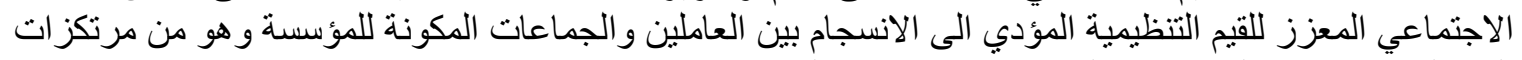

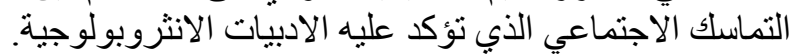

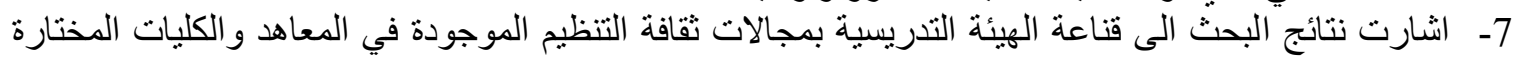

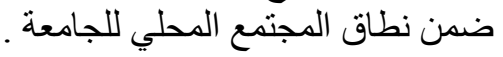

التوصيات

1- تتحقق ثقافة التظظيم بمجاتلاتها( الثقافة الجماعية، الثقافة التطويرية، الثقافة العقلانية، الثقافة الهرمية ومجال التهال

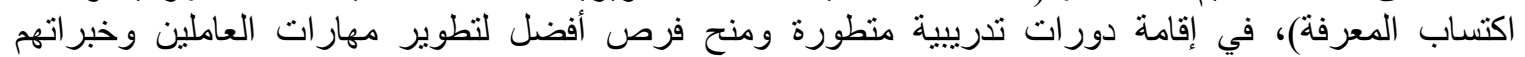

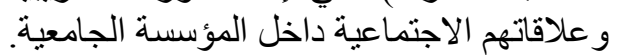

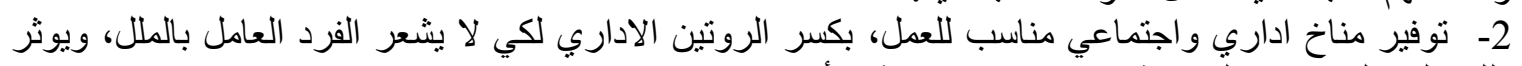

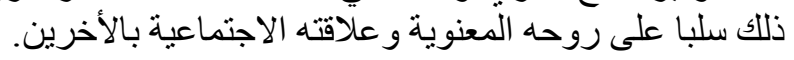

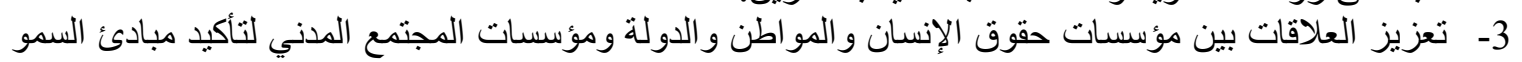

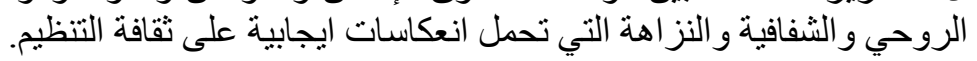

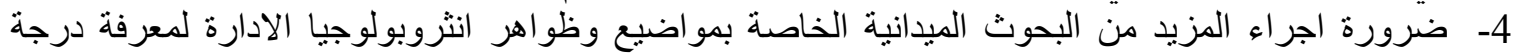

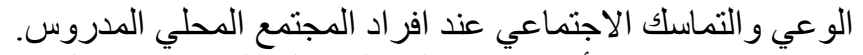

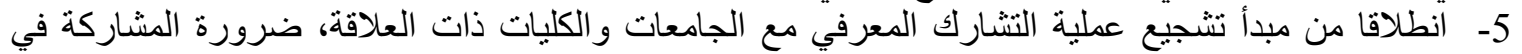

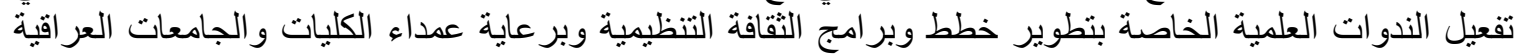
و الاقليمية. 6- ينبخي على اصحاب القرار في الجامعة الاستمر ار في إظهار مستويات عالية من الاهتمام بثقافة التنظيم وجعلها

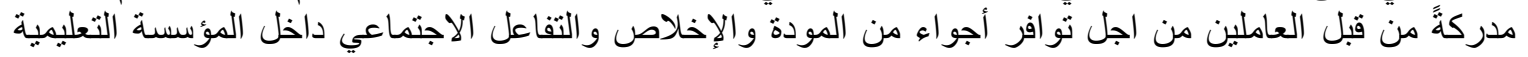
المبحوثة. 


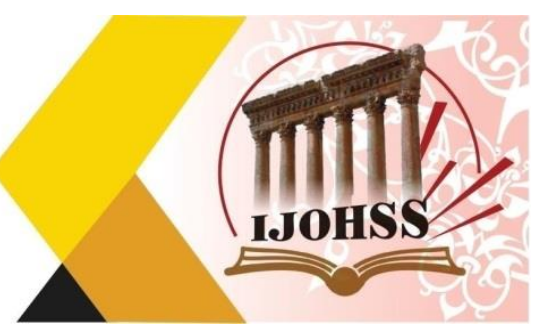

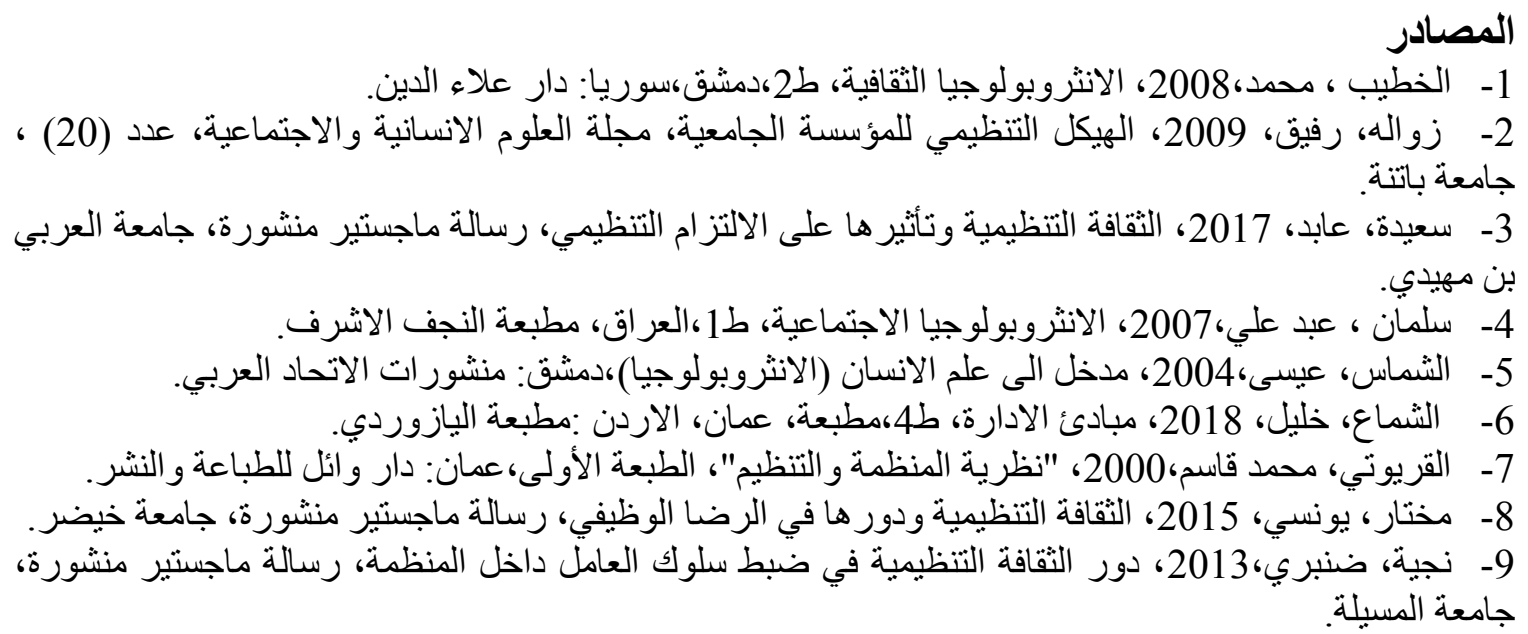

10- Ahmed. B\& Shafiq. S,2014, The Impact of Organizational Culture on Organizational Performance: Study of Telecom Sector, Global Journal of Management and Business Research, 14, 3.

11- Alawi, I., Marzooqi, Y.,\& Mohammed, F,2007, Organizational Culture Knowledge Sharing: Critical Success Factors, Journal of Knowledge Management, 11, 2.

12- Alawi. A, Marzooqi. N,\& Mohammed, F,2007, Organizational Culture Knowledge Sharing: Critical Success Factors, Journal of Knowledge Management, Vol. (11), No. (2). 13- Athayde. S,2014, Introduction Indigenou People, Dams, and Resistance," Tipiti: Journal of the Anthropology of Lowland South America 12 no. 2 , 80-92.

14- Budean, A.; Pitariu, H,2008, Cultura organizat, ionala. Realitat, is, perspective Organizational culture. Realitiesand perspectives]. In Psihologie Organizat,ional Manageriala. Tendint, Actuale Organizational -Managerial Psychology. Current Tendencies]; Avram, E., Cooper, C.L., Eds.; Polirom: Iasi, Romania; pp. 197-221.

15-Czarniawska. B,2012, Organization Theory Meets Anthropology: A Story of an Encounter, Journal of Business Anthropology, 1(1), Spring, pp. 119-1140.

16- Doda. Z,2005, Introduction to Sociocultural Anthropology, LECTURE NOTES For Health Science Students The Carter Center, the Ethiopia Ministry of Health, and the Ethiopia Ministry of Education.

17-Ellinas. C, Allan. N\& Johansson. A,2017, Dynamics of organizational culture: Individual beliefs vs. social conformity, 12, PP. 1-20.

18- Jones, G,1995 Organizational Theory: Text and Cases, U.S.A.

19- Lapina. I, Kairiša. I\& Aramina, D,2015, Role of Organizational Culture in the Quality Management of University. Procedia Soc. Behav. Sci, 213, 770-774.

20- Latour. B,2014, Anthropology at the Time of the Anthropocene: A Personal View of What Is to be Studied, (paper presented at the annual meeting of the American Anthropological Association, Washington ,latour.fr/sites/default/files/139-AAA Washington.pdf. 


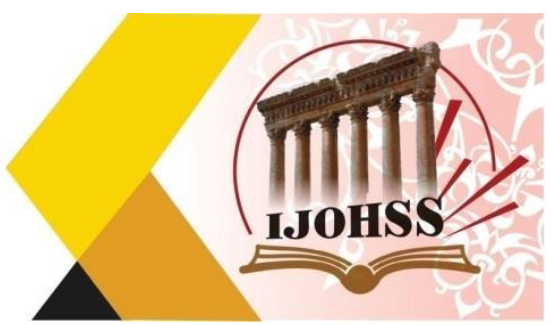

21- Preister, K,2018, The Use of Anthropology as a Management Framework in a Corporate Context: Review and Prospects, Journal of Business Anthropology, 7(1), Spring, pp 76-97.

22- Reed. R,2011, Forest Development and the Indian Way: Reading in Cultural Anthropology, eds. James Spradley and David McCurdy, 105-115 (New York: Pearson). 23-Reisyan, G.D,2016, Neuro-Organizational Culture. A New Approach to Understanding Human Behavior in theWorkplace; Springer: Berlin, Germany.

24- Robbins, P,2003, Organization Behavior, $10^{\text {th }}$ Ed. Hall, Inc., New Jersey.

25- Smith\& Davies.2008, Anthropology For Dummies, , Wiley Publishing, Inc.

26- Spek, R \& Spijkervet, A,2005, Knowledge Management: Dealing Intelligently With Knowledge, $4^{\text {th }}$ Ed., Publications/ IBIT.

27- Stemberger. M, Buh. B, Glavan, L\& Mendling, J,2018, Propositions on the interaction of organizational culture with other factors in the context of BPM adoption. BPMJ, 24, 425-445.

28- Taneja, S., Sewell, S., \& Odom, Y,2015, Culture of Employee Engagement: A Strategic Perspective for Global Managers. Journal of Business Strategy, 36(3).

29- Vlaicu, F, Neagoe, A, Gabriel, L\& Otovescu, A,2019, The Organizational Culture of a Major Social Work Institution in Romania: A Sociological Analysis. Sustainability, PP. $11,2-18$.

30- Wahyuningsih, S, Sudiro.A, Troena. E\& Irawanto.D,2019, Analysis of organizational culture with denison's model approach for international business competitiveness, Problems and Perspectives in Management, Volume 17, Issue 1, 142-151.

31- Wilson, A.M,2001, Understanding organizational culture and the implications for corporate marketing. Eur. J.Mark., 35, 353-367.

32- Ybema, S; Yanow, D; Wels, H, and Kamsteeg, F(eds.),2009, Organizational ethnography: Studying the complexity of everyday life, London: Sage. 